\title{
Cephalometric Measurements Of Non-Syndromic Oligodontia In Early Dental Age In A Japanese Population
}

This article was published in the following Dove Press journal: Clinical, Cosmetic and Investigational Dentistry

\author{
Hisayo Mayama' \\ Yukinori Kuwajima ${ }^{2}$ \\ John D Da Silva $\mathbb{D}^{3}$ \\ Shahrzad Khorashadi ${ }^{2}$ \\ R Frederick Lambert ${ }^{2,4}$ \\ Yoshiki Ishida ${ }^{2}$ \\ Shigemi Ishikawa-Nagai ${ }^{2}$ \\ Hiroyuki Miura ${ }^{5}$ \\ Kazuro Satoh' \\ 'Division of Orthodontics, Department \\ of Developmental Oral Health Science, \\ School of Dentistry Iwate Medical \\ University, Morioka, Iwate, Japan; \\ ${ }^{2}$ Department of Oral Medicine, Immunity \\ and Infection, Harvard School of Dental \\ Medicine, Boston, MA, USA: \\ ${ }^{3}$ Department of Restorative Dentistry \\ and Biomaterials Science, Harvard School \\ of Dental Medicine, Boston, MA, USA; \\ ${ }^{4}$ Department of Health Policy and \\ Management, Harvard T. H. Chan School \\ of Public Health, Boston, MA, USA; \\ ${ }^{5}$ Division of Dental Education, \\ Department of Oral Medicine, School of \\ Dentistry Iwate Medical University, \\ Morioka, Iwate, Japan
}

Correspondence: Shigemi Ishikawa-Nagai Harvard School of Dental Medicine, 188 Longwood Avenue, Boston, MA, USA

Tel $+|-67|-432-2928$

Fax + I-617-432-1897

Email shigemi_nagai@hsdm.harvard.edu
Purpose: Oligodontia significantly affects oral function and esthetics. Recognition of skeletal and dental patterns may aid in proper diagnosis and development of appropriate interventions. The aim of this study was to analyze skeletal and dental patterns for preadolescent patients with a diagnosis of oligodontia.

Patients and methods: This study included 19 oligodontia patients (age: $9.5 \pm 1.3$, Hellman's developmental stage IIIA IIIB) along with a control group that comprised of 19 participants (age: 9.9 \pm 1.6 ) without any skeletal disharmony or congenitally missing teeth, with an Angle class I relationship and general crowding. Average cephalometric measurements among the oligodontia group were compared to the control group. The correlation between number of congenitally missing teeth (CMT) and each measurement was investigated. Skeletal measurements for both male and female patients in the oligodontia group and the control group were also compared.

Results: No significant difference between the experimental and the control group was observed with respect to skeletal angular and linear measurements, except the gonial angle. Differences in dental pattern measurements were observed. The oligodontia group had significantly smaller Mo-Ms and Is-Mo than the control group $(\mathrm{p}<0.01)$. No correlation was detected between severity of oligodontia (number of CMT) and skeletal measurement except for SNB $(\mathrm{R}=-0.4)$. For females with oligodontia, Mo-Ms (eruption of maxillary first molar) and Is-Mo (mesial location of maxillary first molar) significantly differed from females in the control group $(\mathrm{p}<0.01)$. In contrast, no differences in Mo-Ms or Is-Mo were detected for male patients when oligodontia and control group were compared.

Conclusion: Among pre-adolescent Japanese patients with oligodontia in Hellman's developmental age IIIA IIIB, no significant differences in skeletal characteristics were established when compared to the control group. However, tooth position of maxillary first molars indicated smaller vertical descent and mesial shift, which may suggest weak maxillary vertical development.

Keywords: non-syndromic oligodontia, congenitally missing teeth, craniofacial morphology, skeletal and dental pattern

\section{Introduction}

Among the most common dental conditions in the maxillofacial region, congenitally missing teeth (CMT) significantly affects form, function and esthetics. More specifically, oligodontia is a rare genetic disorder which represents the congenital absence of more than six teeth in primary, permanent or both dentitions, excluding third molars. Although a missense mutation (P20L) was identified among patients 
with CMT, definitive etiology for the condition is still unknown. ${ }^{1}$ Comprehensive orthodontic treatment with space opening or closure before prosthetic therapy, bonded resin restorative technique, fabrication of removable or fixed partial dentures, implant-supported restorations, or combinations of the aforementioned treatments are often utilized to treat CMT. ${ }^{2-6}$ Early diagnosis of developmental patterns during growth and proper intervention is critical in achieving long-term treatment success.

Differences in skeletal patterns and craniofacial morphology are both related to CMT. Reports suggest that the skeletal pattern of CMT correlates with a significantly smaller mandibular plane inclination and in more severe cases a prognathic mandible. ${ }^{7-11}$ Sarnas and Rune report that patients who are congenitally missing more than 4 teeth are more retrognathic in the maxilla, and the sagittal jaw relationship angle was smaller than in the average population. ${ }^{12}$ In the vertical dimension, an increasing number of missing teeth correlated with a decrease in the mandibular plane angle and a reduction in facial height. Others, however, report no relationship between the size of the mandible, general growth pattern, lip position, or facial esthetics and CMT. ${ }^{12-15}$

Differences in sample populations, such as age range which significantly affects skeletal growth patterns and craniofacial morphology, may account for contradictory reports. In previous studies, for example, the largest age range of subjects was from 6 to 23 years. ${ }^{8}$ In other studies, the average age varied from 11 to 17 years old. ${ }^{7-11}$ This wide age range includes a broad variety of skeletal growth patterns. Ben-Bassat et al and Gungor et al report that the severity, the number, and the location of congenitally missing teeth affect the skeletal pattern and craniofacial morphology of patients with oligodontia. ${ }^{8,10}$ Their studies include a wide age range of patients of oligodontia among whom skeletal patterns also varied.

Oligodontia presents as congenital absence of more than six teeth, excluding the third molars is quite rare. ${ }^{10,16-18}$ Prevalence of non-syndromic oligodontia is less than $1 \%$ but varies across studied populations. The prevalence in the Turkish population is $0.13 \%$ while in the Japanese population it is $0.05 \%$ to $0.94 \%$. Oligodontia prevalence in other populations such as USA, China, Britain, Canada, Sweden and Malaysia ranges from $0.05 \%$ to $0.43 .{ }^{17,19-23}$ It is difficult to obtain an adequate, balanced sample size and population from which to accurately study oligodontia.

In this present study, we intentionally selected a study sample with a narrow age range, Hellman's developmental stage IIIA (complete eruption of permanent first molar and incisors) to IIIB (exchange phase of lateral teeth) in order to minimize the effects and variations caused by age-related skeletal developmental and eruption of the second molar. Here, we analyzed cephalometric measurements of patients with oligodontia compared to a control group in the Japanese population. Cephalometric analysis included skeletal angular and linear measurements and oligodontia patients only included those missing more than six teeth excluding the third molar. Gender difference and the relationship between CMT severity, skeletal and dental patterns were analyzed.

\section{Materials And Methods}

This study was the retrospective study and approved by the institutional review board (IRB) at Iwate Medical University, School of Dental Medicine (No. 01290), in Japan. First, orthodontic records including lateral cephalometric radiographs of patients at Iwate Medical University School of Dental Medicine during 2005-2015 were reviewed by the principal investigator (PI). Eligible patients were selected based on the following inclusion and exclusion criteria: patients with at least 6 CMT (excluding the third molars) in the permanent teeth in Hellman's developmental stage IIIA IIIB were included. Patients with cleft lip/palate, craniofacial anomalies, and/or diagnosed syndromes were excluded. Potential patients who met the inclusion criteria were informed of the general aim of the study by PI or Co-PI using lay language. For the patients who agreed, informed consent was obtained and participants were offered a copy of the consent information. The personal identification was removed from the records and radiographs so that all research data did not contain any identifiers. All research data were stored in the computer with password protection in a locked room (PI's office). This study was performed under the compliance of Declaration of Helsinki.

Nineteen patients with oligodontia between the ages of 7 and 12 years (mean $9.5 \pm$ SD 1.3) were included. For the control group (Table 1), 19 participants without any skeletal disharmony or congenitally missing teeth and an Angle class I relationship with moderate crowding were included. Skeletal relationship was determined by cephalometric analysis, and dental Angle classification was determined by clinical examination of the first molar relationship. Average age among those in the control group was $9.9 \pm 1.6$ years (range: $6 \pm 12$ years old).

Lateral cephalometric radiographs were taken with the teeth in centric occlusion by cephalostat (Asahiroentgen Ind. Co., Ltd., Kyoto, Japan). These cephalometric radiographs had been taken as part of the routine comprehensive 
Table I Demographic Data Of The Patients Included

\begin{tabular}{|l|l|l|l|l|l|l|l|}
\hline & \multicolumn{2}{|l}{ Control } & \multicolumn{2}{l|}{ Oligodontia } & Total \\
\cline { 2 - 8 } & Female & Male & Sub-Total & Female & Male & Sub-Total \\
\hline $\begin{array}{l}\text { Number of patients } \\
\text { Age (years) }\end{array}$ & 13 & 6 & 19 & 13 & 6 & 19 & 38 \\
\hline
\end{tabular}

orthodontic evaluation of patients and not for the purpose of this study. Radiographic findings, a questionnaire, and clinical exam were used to diagnose CMT. Anatomical landmarks were identified on tracing paper. Cephalometric reference points and lines are illustrated in Figures 1 and 2. Cephalometric measurements (13 skeletal parameters and 6 dental patterns) were used to evaluate skeletal and dental characteristics. $^{24,25}$ Cephalometric analyses were performed with cephalometric software program (Winceph 5.5, Rise Corporation, Sendai, Japan).

\section{Data Analysis}

Cephalometric measurements among oligodontia and control groups were compared using Student's $t$-test $(\mathrm{p}<0.05)$. Pearson's correlation coefficients between number of missing teeth and each cephalometric measurement were calculated. ${ }^{26}$

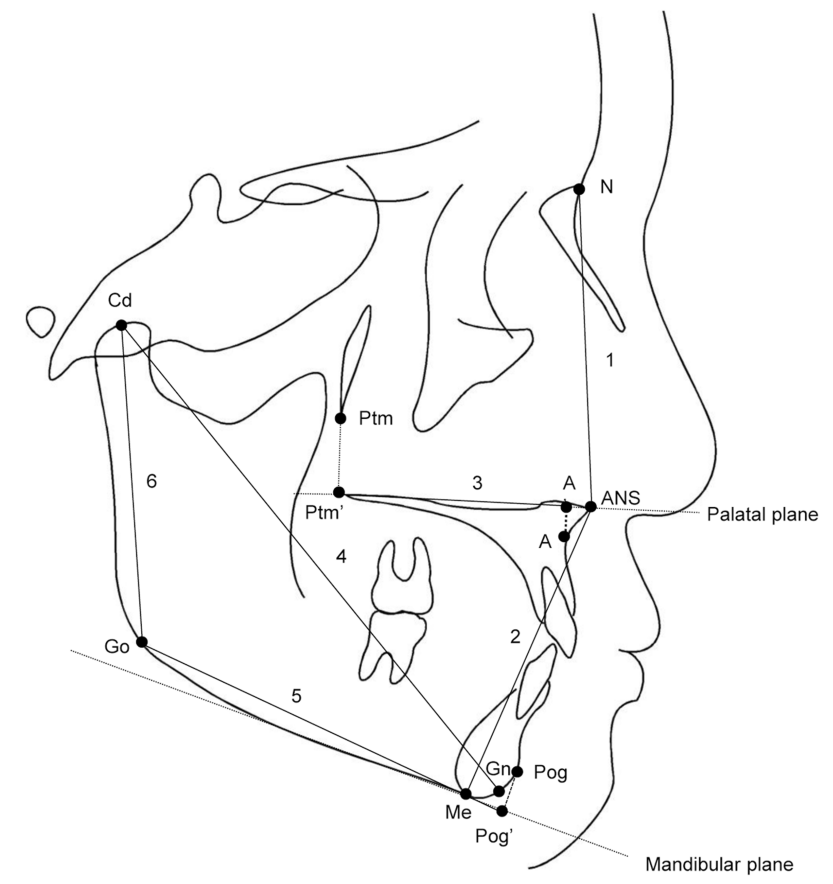

a
Distributions of CMT among females and males with oligodontia were analyzed by Chi-square test. Skeletal measurements of females with oligodontia $(n=13)$ were compared to females in the control group $(n=13)$, and measurements of males with oligodontia $(n=6)$ were compared to males in the control group $(\mathrm{n}=6)$ using a student $t$-test $(\mathrm{p}<0.05)$.

\section{Results}

Number of CMT per patient ranged from 6 to 12 in this study. The most prevalent CMT, among the study participants, were the maxillary second premolar $(22.1 \%)$ and the mandibular second premolar $(22.1 \%)$. Following the premolars, the most prevalent missing teeth were the mandibular first premolar (10.4\%) and the maxillary first premolar $(9.7 \%)$. In this study, congenitally missing first molars were not observed among any of the participants (Table 2).

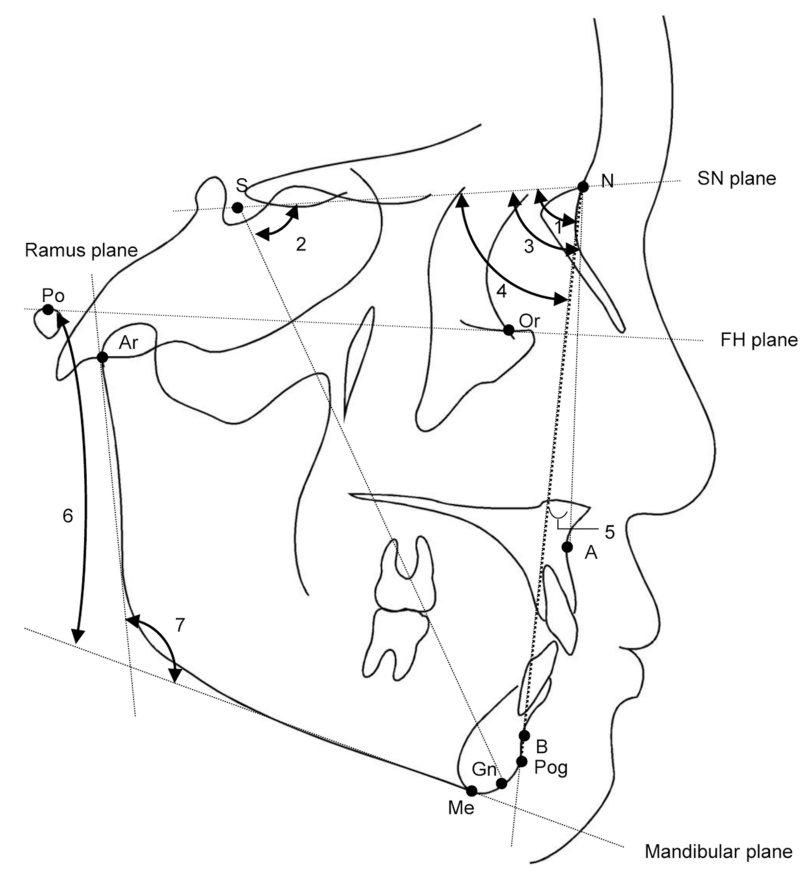

b

Figure I Landmarks for skeletal pattern measurements. (A) Linear measurements: I. N-ANS, 2. ANS-Me, 3. A'-Ptm', 4. Gn-Cd, 5. Pog'-Go, 6. Cd-Go. (B) Angular measurements: I. facial angle, 2. Y-axis, 3. SNA, 4. SNB, 5. ANB, 6. mandibular plane to FH, 7. gonial angle. 


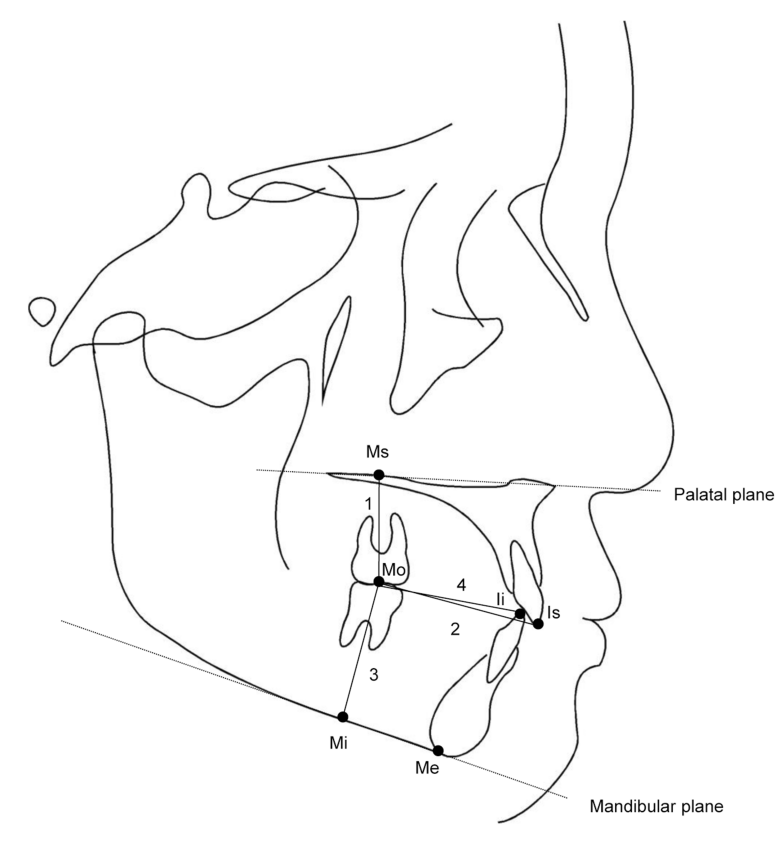

a

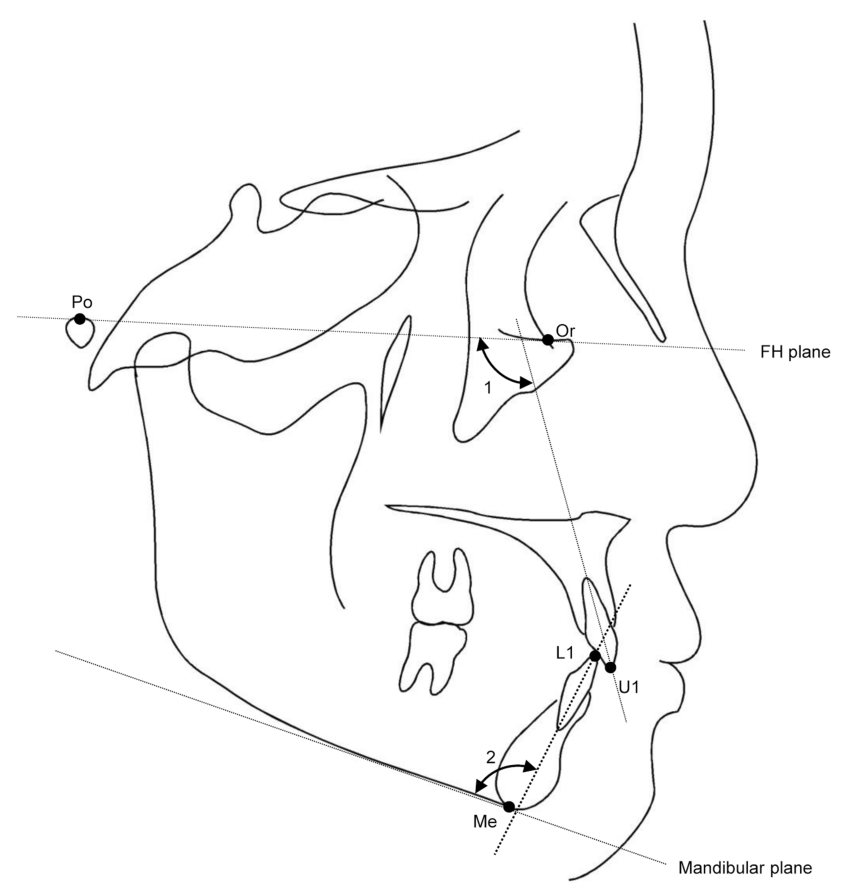

b

Figure 2 Landmarks for dental pattern measurements. (A) Linear measurements: I. Mo-Ms, 2. Is-Mo, 3. Mo-Mi, 4. li-Mo. (B) Angular measurements: I. UI to FH, 2. LI to mandibular plane.

When compared with the control group, participants with oligodontia had significantly smaller Mo-Ms, Is-Mo $(\mathrm{p}<0.01)$, and gonial angle $(\mathrm{p}<0.05$, Table 3$)$. There was no

Table 2 The Number And Rate Of Congenitally Missing Teeth

\begin{tabular}{|l|l|l|}
\hline Type Of Tooth & Number & Rate \\
\hline Maxillary & & \\
Central incisor & 0 & $0.0 \%$ \\
Lateral incisor & 14 & $9.1 \%$ \\
Canine & 13 & $8.4 \%$ \\
First premolar & 15 & $9.7 \%$ \\
Second premolar & 34 & $22.1 \%$ \\
First molar & 0 & $0.0 \%$ \\
Second molar & 10 & $6.5 \%$ \\
Sub-total & 86 & $55.8 \%$ \\
\hline Mandibular & & \\
Central incisor & 5 & $3.2 \%$ \\
Lateral incisor & 6 & $3.9 \%$ \\
Canine & 3 & $1.9 \%$ \\
First premolar & 16 & $10.4 \%$ \\
Second premolar & 34 & $22.1 \%$ \\
First molar & 0 & $0.0 \%$ \\
Second molar & 4 & $2.6 \%$ \\
Sub-total & 68 & $44.2 \%$ \\
\hline Total & 154 & $100 \%$ \\
\hline
\end{tabular}

significant correlation between Mo-Ms $(\mathrm{R}=-0.12)$ and Is-Mo $(\mathrm{R}=0.02)$ measurements and number of $\mathrm{CMT}$, i.e. severity of oligodontia. Only a weak negative correlation was observed between gonial angle $(\mathrm{R}=0.21)$ and number of CMT (Table 4).

In contrast, no significant difference in A'-Ptm', MoMi, Ii-Mo, Y-axis, SNA, and SNB measurement was observed between the oligodontia group and control group (Table 3); however, weak-to-moderate correlations with the number of CMT (severity of oligodontia) were observed (Table 4). Correlation of Mo-Mi $(\mathrm{R}=+0.28)$ and Ii-Mo $(\mathrm{R}=-0.29)$ with the number of CMT indicates that the mandibular molar is extruded and drifts farther forward in the dental arch as the severity of oligodontia increases. Negative correlation of SNA ( $\mathrm{R}=-0.28)$, SNB $(\mathrm{R}=-0.42)$, and $\mathrm{A}^{\prime}-\mathrm{Ptm}$ ' $(\mathrm{R}=-0.25)$ with the number of CMT indicates that with increasing severity of CMT, A'-Ptm' is smaller and both the mandible and maxilla are more posteriorly positioned (Table 4). Lastly, a positive correlation on Y-axis $(\mathrm{R}=+0.22)$ implies mandibular development in a downward and forward direction (Table 4).

No statistically significant difference was detected in the distribution of CMT in both arches $[\mathrm{p}=0.25$; maxillary $(\mathrm{p}=0.08)$ and mandibular $(\mathrm{p}=0.5)]$ among females and males with oligodontia (Table 5). Average linear and 
Table 3 Comparison Of Cephalometric Linear And Angular Measurements On The Control And Oligodontia Group

\begin{tabular}{|c|c|c|c|c|c|}
\hline & \multicolumn{2}{|c|}{ Control } & \multicolumn{2}{|c|}{ Oligodontia } & \multirow[t]{2}{*}{ P-Value } \\
\hline & Mean & S.D. & Mean & S.D. & \\
\hline \multicolumn{6}{|l|}{ Skeletal Pattern } \\
\hline \multicolumn{6}{|l|}{ Linear measurements $(\mathrm{mm})$} \\
\hline N-ANS & 51.2 & 2.9 & 52.1 & 3.3 & 0.406 \\
\hline ANS-Me & 65.5 & 3.9 & 63.2 & 4.0 & 0.098 \\
\hline$A^{\prime}-P_{t m}^{\prime}$ & 46.1 & 1.8 & 45.2 & 3.3 & 0.330 \\
\hline $\mathrm{Gn}-\mathrm{Cd}$ & 106.9 & 4.8 & 105.6 & 5.6 & 0.453 \\
\hline Pog'-Go & 71.1 & 3.1 & 70.6 & 4.2 & 0.721 \\
\hline Cd-Go & 52.1 & 2.3 & 51.6 & 4.8 & 0.680 \\
\hline \multicolumn{6}{|c|}{ Angular measurements (degree) } \\
\hline Facial angle & 83.4 & 1.7 & 83.1 & 2.7 & 0.690 \\
\hline Y-axis & 64.8 & 1.9 & 64.7 & 2.8 & 0.895 \\
\hline SNA & 81.3 & I.I & 80.7 & 3.8 & 0.466 \\
\hline SNB & 76.9 & 1.0 & 77.5 & 3.2 & 0.474 \\
\hline ANB & 4.4 & 0.7 & 3.2 & 3.1 & 0.106 \\
\hline Mandibular plane to $\mathrm{FH}$ & 31.1 & 1.5 & 29.1 & 4.5 & 0.087 \\
\hline Gonial angle & 127.8 & 3.1 & 123.9 & 7.6 & $0.048 *$ \\
\hline \multicolumn{6}{|l|}{ Dental Pattern } \\
\hline \multicolumn{6}{|l|}{ Linear measurements (mm) } \\
\hline Mo-Ms & 19.8 & 1.3 & 17.6 & 2.4 & $0.002 * *$ \\
\hline Is-Mo & 37.1 & 1.5 & 34.4 & 3.1 & $0.002 * *$ \\
\hline Mo-Mi & 30.0 & 1.4 & 30.5 & 2.7 & 0.526 \\
\hline li-Mo & 32.2 & 1.0 & 32.3 & 2.8 & 0.911 \\
\hline \multicolumn{6}{|c|}{ Angular measurements (degree) } \\
\hline $\mathrm{UI}$ to $\mathrm{FH}$ & 110.3 & 5.3 & 110.4 & 5.5 & 0.972 \\
\hline LI to mandibular plane & 94.8 & 4.2 & 93.2 & 7.1 & 0.417 \\
\hline
\end{tabular}

Notes: $* \mathrm{P}<0.05, * * \mathrm{P}<0.01$.

angular measurements differed significantly among females with oligodontia when compared to female controls. Only average angular measurements differed significantly among males with oligodontia compared with male controls. Females with oligodontia had significantly smaller average ANS-Me $(\mathrm{p}<0.05)$, Mo-Ms $(\mathrm{p}<0.01)$ and IsMo $(p<0.01)$ measurements than female controls. The male group had a smaller mandibular Pl to FH $(p<0.05)$ than the control. The average U1 to FH measurement among female participants with oligodontia was smaller than the control group, though not significantly; but among males with oligodontia, the average U1 to $\mathrm{FH}$ measurement was significantly larger than among male controls $(\mathrm{p}<0.05$, Table 6).

\section{Discussion}

The average age of participants with oligodontia $(9.5 \pm 1.3$ years old) and the narrow age range ( 7 to 12 years) relative to previous reports make this study particularly significant. ${ }^{7,27,28}$ The analysis was restricted to Hellman's developmental stage IIIA and IIIB in order to limit the effects of second molar eruption (e.g. increase of vertical dimension and changes in craniofacial morphology). Exclusion of patients with hypodontia (fewer than 6 CMT) led to a smaller but more specific study population when compared to other studies. Distribution of CMT in this study was similar to previous studies with the highest prevalence occurring in the second premolar (maxillary and mandibular) followed by the maxillary lateral incisor and the mandibular first premolar. ${ }^{29}$ Similar to previous reports, participants with oligodontia had a smaller gonial angle, smaller angle of mandibular plane to $\mathrm{FH}$ and ANS-Me compared to controls. ${ }^{7-11,17}$ The above measurements among a cohort of participants with oligodontia of younger average age than previous studies may suggest that those with oligodontia may, on average, have a low 
Table 4 The Correlation Between The Number Of Missing Teeth And Cephalometric Measurements

\begin{tabular}{|l|l|l|l|}
\hline Skeletal Pattern & & & \\
\hline Linear & $\mathrm{R}$ & $\begin{array}{l}\text { Angular measurements } \\
\text { (degree) }\end{array}$ & $\mathrm{R}$ \\
N-ANS & 0.13 & $\begin{array}{l}\text { Facial angle } \\
\text { YNS-Me }\end{array}$ & -0.09 \\
A'-Ptm' & 0.12 & Y-axis & $0.22^{*}$ \\
Gn-Cd & $-0.25^{*}$ & SNA & $-0.28^{*}$ \\
Pog'-Go & -0.06 & SNB & $-0.42^{* *}$ \\
Cd-Go & 0.18 & ANB & 0.10 \\
& 0.03 & Mandibular plane to FH & 0.01 \\
& & Gonial angle & $-0.21^{*}$ \\
\hline Dental Pattern & & & \\
\hline Linear & & Angular measurements & \\
measurements (mm) & & (degree) & \\
Mo-Ms & -0.12 & Ul to FH & -0.06 \\
Is-Mo & 0.02 & LI to mandibular plane & -0.19 \\
Mo-Mi & $0.28^{*}$ & & \\
li-Mo & $-0.29 *$ & & \\
\hline
\end{tabular}

Notes: $*|\mathrm{R}|>0 . \mathrm{I}, * *|\mathrm{R}|>0.4$.

angle skeletal pattern early in development. Regardless of the average age, those with oligodontia had smaller Mo-Ms and Is-Mo measurements compared to controls, indicating a weak eruption and mesial location of the maxillary first molar. Furthermore, neither measurement correlated with severity of oligodontia. These findings are predictors of a future class III skeletal relationship among patients with oligodontia. Average Mo-Mi, Ii-Mo, Y-axis, SNA, SNB and A'-Ptm' measurements were moderately correlated with severity of oligodontia and are significant for predicting future skeletal development of both jaws.

Gender differences in the dental pattern characteristics of oligodontia in this study suggest that females with oligodontia have a lower eruption and more mesial location of the maxillary first molar compared to controls. Males with oligodontia did not have those dental characteristics. On average, skeletal development of the maxilla is completed at 15 years of age in females and 17 years of age in males. ${ }^{9}$ The peak of maxillary skeletal development is around 8 to 10 years of age and the peak for males is 1 to 2 years later than females. ${ }^{30,31}$ Therefore, the average measurements of MoMs, Is-Mo and ANS-Me among males with oligodontia should not be significantly different compared to male controls in the age range of the selected study population (9.1 \pm 1.0 for male and $9.7 \pm 1.3$ for female).

Currently, oligodontia is rarely diagnosed by Hellman's developmental stage IIIA because symptoms of CMT are not clinically detectable and panoramic radiography is not frequently used in this age group. Although there was no significant difference in the skeletal patterns of the oligodontia group early in development, the dental pattern of maxillary first molar differed significantly from the control group. This study highlights the importance of early diagnosis of oligodontia. Early diagnosis of oligodontia from Hellman's developmental stage IIIA to IIIB may facilitate better treatment outcomes through available treatments such as growth modification via orthodontics, molar extrusion, and increase/maintenance of vertical dimension. Early diagnosis and intervention may obviate the need for more invasive procedures such as orthognathic surgery and could create a more ideal dental arch, occlusal plane, and vertical dimension for final comprehensive restorative treatments to achieve optimal esthetics and function.

Limitations of this study include a small study population and sample size. All patients, including controls, were collected from Japanese orthodontic patients, which limits the generalizability of the study, and, therefore, the results cannot be directly applicable to other ethnic groups. Although sample size calculation is not necessary for this type of study, if we applied the formula $[\mathrm{n}=2 \times(\mathrm{SD} / \Delta) 2 \times$ 7.9] to all cephalometric measurements, average $n$ is 18.7 .

Table 5 The Distribution Of CMT In Female And Male Group

\begin{tabular}{|c|c|c|c|c|c|c|c|}
\hline & \multicolumn{3}{|c|}{ Maxillary } & \multicolumn{3}{|c|}{ Mandibular } & \multirow[t]{2}{*}{ Total } \\
\hline & Female & Male & Sub-total & Female & Male & Sub-total & \\
\hline Central incisor & 0 & 0 & 0 & 4 & I & 5 & 5 \\
\hline Lateral incisor & 11 & 3 & 14 & 4 & 2 & 6 & 20 \\
\hline Canine & 7 & 6 & 13 & 1 & 2 & 3 & 16 \\
\hline First premolar & 8 & 7 & 15 & 10 & 6 & 16 & 31 \\
\hline Second premolar & 23 & 11 & 34 & 24 & 10 & 34 & 68 \\
\hline First molar & 0 & 0 & 0 & 0 & 0 & 0 & 0 \\
\hline Second molar & 10 & 0 & 10 & 4 & 0 & 4 & 14 \\
\hline
\end{tabular}


Table 6 Comparison Between Oligodontia And Control By Gender

\begin{tabular}{|c|c|c|c|c|c|}
\hline \multirow[t]{2}{*}{ Female } & \multicolumn{2}{|c|}{ Control } & \multicolumn{2}{|c|}{ Oligodontia } & \multirow[t]{2}{*}{ P-Value } \\
\hline & Mean & S.D. & Mean & S.D. & \\
\hline \multicolumn{6}{|l|}{ Skeletal Pattern } \\
\hline \multicolumn{6}{|l|}{ Linear measurements (mm) } \\
\hline N-ANS & 50.6 & 3.0 & 52.3 & 3.3 & 0.215 \\
\hline ANS-Me & 65.7 & 4.5 & 62.1 & 3.8 & $0.042 *$ \\
\hline$A^{\prime}-P_{t m}^{\prime}$ & 46.2 & 1.5 & 44.3 & 3.1 & 0.063 \\
\hline $\mathrm{Gn}-\mathrm{Cd}$ & 107.6 & 5.2 & 104.0 & 4.6 & 0.084 \\
\hline Pog'-Go & 71.6 & 3.3 & 70.3 & 4.4 & 0.453 \\
\hline Cd-Go & 52.4 & 2.4 & 50.8 & 5.3 & 0.370 \\
\hline \multicolumn{6}{|c|}{ Angular measurements (degree) } \\
\hline Facial angle & 83.8 & 1.4 & 82.4 & 2.9 & 0.141 \\
\hline Y-axis & 64.4 & 1.9 & 65.5 & 2.5 & 0.215 \\
\hline SNA & 81.5 & 1.2 & 80.3 & 4.1 & 0.381 \\
\hline SNB & 77.4 & 0.9 & 77.1 & 2.4 & 0.689 \\
\hline ANB & 4.1 & 0.6 & 3.3 & 3.4 & 0.416 \\
\hline Mandibular plane to $\mathrm{FH}$ & 30.9 & 1.4 & 29.7 & 4.9 & 0.431 \\
\hline Gonial angle & 127.8 & 3.5 & 122.3 & 8.5 & 0.051 \\
\hline \multicolumn{6}{|l|}{ Dental Pattern } \\
\hline \multicolumn{6}{|l|}{ Linear measurements $(\mathrm{mm})$} \\
\hline Mo-Ms & 19.9 & 1.4 & 17.1 & 2.3 & $0.002^{* *}$ \\
\hline Is-Mo & 37.1 & 1.7 & 33.2 & 2.8 & $0.000 * *$ \\
\hline Mo-Mi & 29.8 & 1.5 & 30.4 & 3.2 & 0.505 \\
\hline li-Mo & 31.8 & 0.9 & 31.5 & 2.6 & 0.652 \\
\hline \multicolumn{6}{|c|}{ Angular measurements (degree) } \\
\hline $\mathrm{UI}$ to $\mathrm{FH}$ & 112.1 & 4.4 & 109.1 & 5.8 & 0.164 \\
\hline LI to mandibular plane & 94.8 & 4.5 & 93.2 & 7.8 & 0.543 \\
\hline \multirow[t]{2}{*}{ Male } & \multicolumn{2}{|c|}{ Control } & \multicolumn{2}{|c|}{ Oligodontia } & \multirow[t]{2}{*}{ P-value } \\
\hline & Mean & S.D. & Mean & S.D. & \\
\hline \multicolumn{6}{|l|}{ Skeletal Pattern } \\
\hline \multicolumn{6}{|l|}{ Linear measurements $(\mathrm{mm})$} \\
\hline N-ANS & 52.6 & 2.1 & 51.8 & 3.2 & 0.640 \\
\hline ANS-Me & 64.9 & 2.1 & 65.7 & 3.3 & 0.655 \\
\hline$A^{\prime}-P_{t m}^{\prime}$ & 45.7 & 2.3 & 47.2 & 2.7 & 0.378 \\
\hline $\mathrm{Gn}-\mathrm{Cd}$ & 105.4 & 3.4 & 109.1 & 5.9 & 0.252 \\
\hline Pog'-Go & 70.0 & 2.2 & 71.3 & 3.6 & 0.526 \\
\hline Cd-Go & 51.6 & 2.1 & 53.3 & 3.1 & 0.343 \\
\hline \multicolumn{6}{|c|}{ Angular measurements (degree) } \\
\hline Facial angle & 82.5 & 1.9 & 84.6 & 1.2 & 0.070 \\
\hline Y-axis & 65.6 & 1.6 & 62.8 & 2.4 & 0.051 \\
\hline SNA & 81.1 & 0.7 & 81.4 & 2.7 & 0.844 \\
\hline SNB & 75.9 & 0.2 & 78.4 & 4.4 & 0.238 \\
\hline ANB & 5.1 & 0.5 & 3.0 & 2.3 & 0.068 \\
\hline Mandibular plane to $\mathrm{FH}$ & 31.5 & 1.8 & 27.8 & 3.3 & $0.050 *$ \\
\hline Gonial angle & 128.0 & 1.8 & 127.3 & 3.3 & 0.662 \\
\hline
\end{tabular}

(Continued) 
Table 6 (Continued).

\begin{tabular}{|c|c|c|c|c|c|}
\hline \multicolumn{6}{|l|}{ Dental Pattern } \\
\hline \multicolumn{6}{|l|}{ Linear measurements $(\mathrm{mm})$} \\
\hline Mo-Ms & 19.7 & I.I & 18.7 & 2.3 & 0.386 \\
\hline Is-Mo & 37.3 & I.I & 37.1 & 1.2 & 0.842 \\
\hline Mo-Mi & 30.6 & 0.8 & 30.6 & 0.9 & 0.927 \\
\hline li-Mo & 33.0 & 0.4 & 34.1 & 2.3 & 0.333 \\
\hline \multicolumn{6}{|c|}{ Angular measurements (degree) } \\
\hline $\mathrm{UI}$ to $\mathrm{FH}$ & 106.4 & 5.0 & 113.2 & 3.4 & $0.033^{*}$ \\
\hline LI to mandibular plane & 94.7 & 3.4 & 93.2 & 5.2 & 0.587 \\
\hline
\end{tabular}

Notes: ${ }^{*} \mathrm{P}<0.05,{ }^{*} \mathrm{P}<0.01$.

Therefore, 19 patients for each experimental and control group in this study are justified. A future study with a larger sample size would allow an analysis of the association between number, type and location of missing teeth and skeletal pattern.

\section{Conclusion}

Patients with oligodontia in Hellman's developmental stage IIIA to IIIB display significant characteristics in the dental pattern (Mo-Ms and Is-Mo) and gonial angle when compared to the control group. Our data indicate that early diagnosis and intervention including growth modification and molar extrusion may contribute to successful longterm treatment outcomes.

\section{Acknowledgment}

We would like to thank Drs. Shinji Furukawa, Taisuke Endo and Akiko Murakami for collecting patient data.

\section{Disclosure}

The authors declare that they have no conflicts of interest in this work.

\section{References}

1. Murakami A, Yasuhira S, Mayama H, Miura H, Maesawa C, Satoh K. Characterization of PAX9 variant P20L identified in a Japanese family with tooth agenesis. PLoS One. 2017;12(10):e0186260. doi:10.1371/ journal.pone. 0186260

2. Wagenberg BD, Spitzer DA. Therapy for a patient with oligodontia: case report. J Periodontol. 2000;71(3):510-516. doi:10.1902/jop.2000.71.3.510

3. Bergendal B. Prosthetic habilitation of a young patient with hypohidrotic ectodermal dysplasia and oligodontia: a case report of 20 years of treatment. Int J Prosthodont. 2001;14(5).

4. Bural C, Oztas E, Ozturk S, Bayraktar G. Multidisciplinary treatment of non-syndromic oligodontia. Eur J Dent. 2012;6(2):218-226.

5. Kuroda S, Iwata M, Tamamura N, et al. Interdisciplinary treatment of a nonsyndromic oligodontia patient with implant-anchored orthodontics. Am J Orthod Dentofacial Orthop. 2014;145(4):S136-S147. doi:10. 1016/j.ajodo.2013.06.023
6. Filius MAP, Kraeima J, Vissink A, Janssen KI, Raghoebar GM, Visser A. Three-dimensional computer-guided implant placement in oligodontia. Int J Implant Dent. 2017;3(1):30. doi:10.1186/s40729-017-0090-6

7. Nodal M, Kjaer I, Solow B. Craniofacial morphology in patients with multiple congenitally missing permanent teeth. Eur J Orthod. 1994;16(2):104-109. doi:10.1093/ejo/16.2.104

8. Ben-Bassat Y, Brin I. Skeletal and dental patterns in patients with severe congenital absence of teeth. Am J Orthod Dentofacial Orthop. 2009;135(3):349-356. doi:10.1016/j.ajodo.2008.09.002

9. Chan DW, Samman N, McMillan AS. Craniofacial profile in Southern Chinese with hypodontia. Eur J Orthod. 2009;31(3):300305. doi:10.1093/ejo/cjn111

10. Gungor AY, Turkkahraman H. Effects of severity and location of nonsyndromic hypodontia on craniofacial morphology. Angle Orthod. 2013;83(4):584-590. doi:10.2319/091012-722.1

11. Bondarets N, McDonald F. Analysis of the vertical facial form in patients with severe hypodontia. Am $J$ Phys Anthropol. 2000;111(2):177-184. doi:10.1002/(SICI)1096-8644(200002)111: $2<177::$ AID-AJPA4 $>3.0 . \mathrm{CO} ; 2-8$

12. Sarnas KV, Rune B. The facial profile in advanced hypodontia: a mixed longitudinal study of 141 children. Eur J Orthod. 1983;5 (2):133-143. doi:10.1093/ejo/5.2.133

13. Ben-Bassat Y, Brin I. Skeletodental patterns in patients with multiple congenitally missing teeth. Am J Orthod Dentofacial Orthop. 2003;124(5):521-525. doi:10.1016/s0889-5406(03)00620-6

14. Jamsa T, Alvesalo L. Size of the mandible related to hypodontia. Proc Finn Dent Soc Suomen Hammaslaakariseuran Toimituksia. 1980;76(4):214-218.

15. Roald KL, Wisth PJ, Boe OE. Changes in cranio-facial morphology of individuals with hypodontia between the ages of 9 and 16. Acta Odontol Scand. 1982;40(2):65-74. doi:10.3109/00016358209041117

16. Chung CJ, Han JH, Kim KH. The pattern and prevalence of hypodontia in Koreans. Oral Dis. 2008;14(7):620-625. doi:10.1111/ j.1601-0825.2007.01434.x

17. Altug-Atac AT, Erdem D. Prevalence and distribution of dental anomalies in orthodontic patients. Am J Orthod Dentofacial Orthop. 2007;131(4):510-514. doi:10.1016/j.ajodo.2005.06.027

18. Celikoglu M, Kazanci F, Miloglu O, Oztek O, Kamak H, Ceylan I. Frequency and characteristics of tooth agenesis among an orthodontic patient population. Med Oral Patol Oral Cir Bucal. 2010;15(5): e797-e801. doi:10.4317/medoral.15.e797

19. Goya HA, Tanaka S, Maeda T, Akimoto Y. An orthopantomographic study of hypodontia in permanent teeth of Japanese pediatric patients. J Oral Sci. 2008;50(2):143-150.

20. Shimizu T, Maeda T. Prevalence and genetic basis of tooth agenesis. Jpn Dent Sci Rev. 2009;45(1):52-58. doi:10.1016/j.jdsr.2008.12.001

21. Endo T, Ozoe R, Kubota M, Akiyama M, Shimooka S. A survey of hypodontia in Japanese orthodontic patients. Am J Orthod Dentofacial Orthop. 2006;129(1):29-35. doi:10.1016/j.ajodo.2004.09.024 
22. O'Dowling I, McNamara T. Congenital absence of permanent teeth among Irish school-children. J Ir Dent Assoc. 1990;36(4):136-138.

23. Muller TP, Hill IN, Peterson AC, Blayney JR. A survey of congenitally missing permanent teeth. J Am Dent Assoc. 1970;81(1):101107. doi:10.14219/jada.archive.1970.0151

24. Iizuka T. Roentgencephalometric analysis of craniofacial growth in Japanese children. J Stomatol Soc Jpn. 1958;25:18-30.

25. Masaki F. The longitudinal study of morphological differences in the cranial base and facial structure between Japanese and American whites. Nippon Kyosei Shika Gakkai Zasshi. 1980;39:436-456.

26. Schober P, Boer C, Schwarte LA. Correlation coefficients: appropriate use and interpretation. Anesth Analg. 2018;126(5):1763-1768. doi:10.1213/ANE.0000000000002864

27. Takahashi Y, Higashihori N, Yasuda Y, Takada JI, Moriyama K. Examination of craniofacial morphology in Japanese patients with congenitally missing teeth: a cross-sectional study. Prog Orthod. 2018;19(1):38. doi:10.1186/s40510-018-0238-9
28. Ogaard B, Krogstad O. Craniofacial structure and soft tissue profile in patients with severe hypodontia. Am J Orthod Dentofacial Orthop. 1995;108(5):472-477. doi:10.1016/s08895406(95)70047-1

29. Higashihori N, Takada JI, Katayanagi M, Takahashi Y, Moriyama K. Frequency of missing teeth and reduction of mesiodistal tooth width in Japanese patients with tooth agenesis. Prog Orthod. 2018;19(1):30. doi:10.1186/s40510-018-0222-4

30. Harris JA, Jackson CM, Paterson DG, Scammon RE. The Measurement of Man. Oxford, England: Univ. Minnesota Press; 1930.

31. Mizuta Y, Nojima K, Nishii Y, Tachiki C, Sueishi K. Comparison of change in maxillofacial morphology and growth between surgical Class III patients receiving orthognathic surgery after orthodontic treatment and those receiving orthodontic treatment alone. Shikwa Gakuho. 2012;112(5):610-619.

\section{Publish your work in this journal}

Clinical, Cosmetic and Investigational Dentistry is an international, peer-reviewed, open access, online journal focusing on the latest clinical and experimental research in dentistry with specific emphasis on cosmetic interventions. Innovative developments in dental materials, techniques and devices that improve outcomes and patient satisfaction and preference will be highlighted. The manuscript management system is completely online and includes a very quick and fair peer-review system, which is all easy to use. Visit http://www.dovepress.com/testimonials.php to read real quotes from published authors. 